\title{
Experimental Investigation of Turbulence Specifications of Turbidity Currents
}

\author{
B. Firoozabadi, H. Afshin and A. Bagherpour \\ School of Mechanical Engineering, Sharif University of Technology, Tehran 11365-9567, Iran \\ Email: h_afshin@mech.sharif.edu
}

(Received January 5, 2008; accepted May 24, 2009)

\begin{abstract}
The present study investigates the turbulence characteristic of turbidity current experimentally. The three-dimensional Acoustic-Doppler Velocimeter (ADV) was used to measure the instantaneous velocity and characteristics of the turbulent flow. The experiments were conducted in a three-dimensional channel for different discharge flows, concentrations, and bed slopes. Results are expressed at various distances from the inlet, for all flow rates, slopes and concentrations as the distribution of turbulence energy, Reynolds stress and the turbulent intensity. It was concluded that the maximum turbulence intensity happens in both the interface and near the wall. Also, it was observed that the turbulence intensity reaches its minimum where maximum velocity occurs.
\end{abstract}

Keywords: Turbidity currents, Turbulence, Laboratory experiment, ADV.

\section{NOMENCLATURE}

$\begin{array}{ll}\rho & \text { Density of The Mixture } \\ \rho_{s} & \text { mixture Density } \\ v & \text { Viscosity of Fluid } \\ \mathrm{g}^{\prime} & \text { Gravitational Acceleration } \\ \mathrm{u}^{\prime}, \mathrm{v}^{\prime}, \mathrm{w}^{\prime} & \text { Root-Mean-Square } \\ \mathrm{Ri} & \text { Richardson number } \\ \mathrm{Re} & \text { Reynolds number } \\ f_{\max } & \text { Maximum Response Frequency } \\ \mathrm{L} & \text { Macro Scale } \\ l & \text { Micro Scale } \\ \mathrm{C} & \text { Concentration } \\ U & \text { X- Velocity } \\ \overline{u w} & \text { turbulence flux covariance } \\ \mathrm{Ri}_{0} & \text { Inlet Richardson number } \\ \mathrm{Ri}_{\mathrm{g}} & \text { gradient Richardson number } \\ \sigma & \text { standard deviation }\end{array}$

\section{INTRODUCTION}

Turbidity current is a mainly straight flow in a gravitational field that is driven by a density difference. These currents are continuous currents which move down slope due to density differences. In the turbidity currents, the density difference can arise from suspended solids such as kaolin or clay. These affect the gravity which is an actual driving force of such flows. Typically, the density difference is small enough for the Boussinesq approximation to be valid. Turbidity

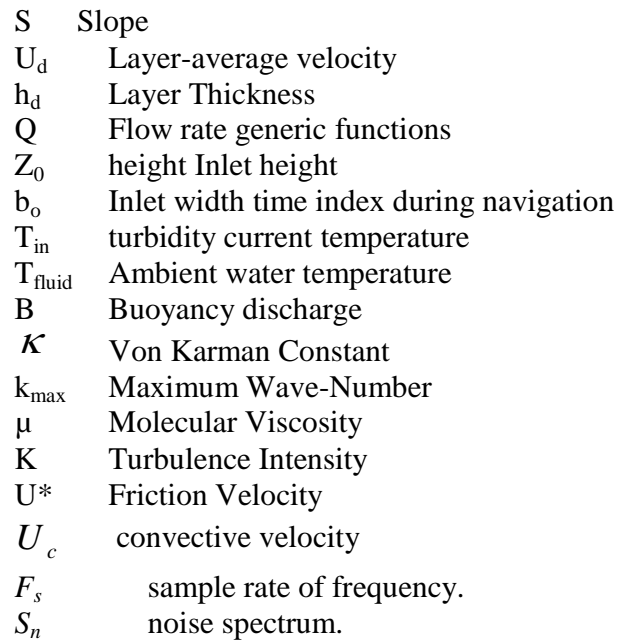

currents are able to transport material across large horizontal distances. For example, these currents on the seafloor may carry material thousands of kilometers.

Spectacular turbidity currents are usually seen in natural such as in the oceans, lakes, atmosphere and etc. Many investigations were performed on velocity structure of turbidity currents such as Ellison \& Turner (1959), Elder and Wunderlich (1972), Hebbert et al. (1979), Britter and Simpson (1978), Simpson (1972), Britter and Linden (1980) and Garcia (1994). 
Kneller et al. (1999) used Laser-Doppler Anemometry to provide a two dimensional picture of a fixed volume saline underflow in the laboratory. They developed a relation for velocity profile and concluded that the maximum amount of turbulence occurs near the upper edge of the flow and length scales of eddies is about the flow thickness. Best et al. (2001) used Ultrasonic Doppler velocity profiling (UDVP) and investigated turbulence structure of semi-steady density currents in a horizontal channel. Buckee et al. (2001) used Laser Doppler anemometry (LDA) and studied vertical distribution of turbulence in density currents. They performed experimental studies of the behavior and turbulence intensity of the density currents. They explained the density stratification is an important control on the distribution of turbulent kinetic energy. In fact, Buckee et al. (2001) identified a slow diffusion zone characterized by low turbulence intensities and reduced vertical mass transport in the lower part of current and reduced turbulence production around the velocity maximum.

Although many studies have been performed in the turbidity currents, the turbulent structures of the turbidity currents are not fully understood and it is essential that the dynamics of these flows and mechanism of turbulence production is completely investigated. Characterizing of the flow and specifically the layer near the bed can help to find the effect of gravity current on the bed and predict the behavior of sediment laden gravity currents. In order to understand the turbulence characteristics of turbidity currents, it is necessary to investigate turbulence structure of these currents experimentally. However, turbulence, that has a principal role on turbidity current behavior, could not be studied in detail due to inherent technical problems. For example the flow is usually opaque so the imaging techniques (laser Doppler anemometry (LDA) or particle image velocimetry (PIV)) cannot be used. Flow visualization techniques have been used to study the internal structure in experimental turbidity currents by Pantin and Leeder (1987) and Edwards et al. (1994) but cannot be used to quantify the turbulence structure. Recently, using of Laser Doppler Anemometry in refractive index matched flows has permitted high resolution velocity data to be collected non-intrusively from simple solute-driven gravity currents and so enabling the turbulence structure to be examined (Kneller et al. 1997, 1999). However, this instrument is only able to gather data for very short intervals (about 5 second) for analysis in these currents.

Recently, Acoustic-Doppler Velocimeter (ADV) and Ultrasonic Doppler velocity profiling (UDVP) has allowed one-dimensional resolution of the flow field in quasi-steady turbidity currents.

In this study, turbulence structure of turbidity current is investigated in the three-dimensional channel in the different discharge flows, concentrations, and bed slopes at Sharif University lab. The instantaneous velocities and turbulence characteristics were measured by an Acoustic Doppler Velocimeter (ADV). Results will be expressed at various distances from the inlet, for all flow rates, slopes and concentrations as the distribution of turbulence energy, Reynolds stress and the turbulent intensity.

\section{EXPERIMENTAL SETUP}

A laboratory apparatus was built to study threedimensional flows resulting from the release of turbid water on a sloping surface in a channel of fresh water $12 \mathrm{~m}$ long, $1.5 \mathrm{~m}$ wide and $0.6 \mathrm{~m}$ high. One side of this channel was constructed of glass for observation. As seen in Fig. 1, the channel was divided into two parts in the longitudinal direction by a separating Plexiglas sheet. The shorter upstream section was an accumulator for dense water with an outlet in the middle bottom of separating Plexiglas sheet with a rectangular cross section and was controlled by a gate. In all experiments, the opening of the gate was set to $1 \mathrm{~cm}$ high. The ratio of the inlet gate opening $\left(z_{0}=1 \mathrm{~cm}\right)$ to the above water depth at the inlet was about $0.02(1 \mathrm{~cm} / 50 \mathrm{~cm})$ or less during the experiments in order to avoid the large recirculation due to depth limitation.

The remaining part of the channel was previously filled with fresh water and its temperature kept as the laboratory temperature. As the test began, the dense water continuously left the reservoir through the outlet and moved along the channel bed. The slope of the channel could be adjusted in the range of $0 \%$ to $3.5 \%$. The salt-solution gradually spread under the fresh water. To avoid the return flow, a $25 \mathrm{~cm}$ step was constructed at the end of the channel. Sixty-four valves with a flow rate about $0.2 \mathrm{lit} / \mathrm{min}$ were installed at the bottom of the step. The number of the opening valves was dictated by the inlet flow to set the discharge rate a little more than the inflow rate to let the entrained water out of the channel. To prevent loosing fresh water, we resupplied the fresh water at the end of the channel so that the total height of fresh water was kept constant during the experiments. The channel overflow prevents over resupplying the fresh water.

A reservoir tank with a maximum capacity of $2 \mathrm{~m}^{3}$ was used to prepare the mixture of the dense water. This tank was made of stainless steel and installed at an elevation of $2.5 \mathrm{~m}$ from the ground. A supplying pipe fed the dense water from the reservoir into the accumulator and a gate valve controlled the feed rate. The feed rate was measured by an ultrasonic flow meter and fixed at a desired rate. Thus, the current was in a quasi-steady condition. After mixing kaolin with fresh water in the reservoir tank, and before feeding into the accumulator, it was transferred to a weir by another circulation pump. The purpose of using this weir was to keep the dense water head constant and to prevent the impacts of fluctuations in mixing reservoirs on the feed rate. The velocity profiles were measured by the 10 $\mathrm{MHz}$ ADV (Acoustic Doppler Velocimeter) made by Nortek Company.

In the present work, the distance between the two sensors of ADV which were placed on a rail conveyor on the channel was $1 \mathrm{~m}$. By changing the vertical location of sensors, the velocity profile of any specific section was determined. The data acquisition took 40$45 \mathrm{sec}$. for each probe's position. The measurement started form the top part of the dense layer and continued into the lower part by dipping probes into the dense layer until all the desired positions were selected. 


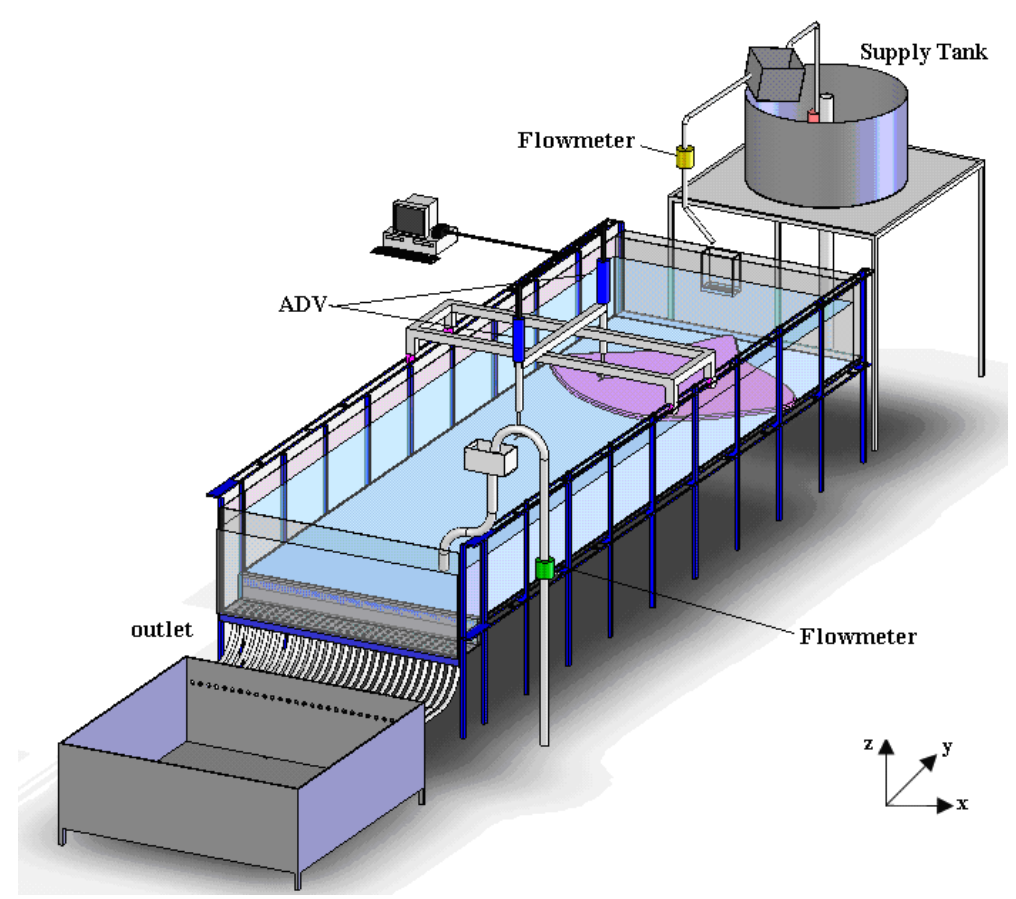

Fig. 1. Schematic of the experiment setup

The total duration of each experiment was about 80 minutes.

\section{EXPERIMENTAL RESUltS}

Table 1 includes the test data. Each part of the test was performed twice in order to reduce the experiment errors. In all experiments the inlet height and width has been $z_{0}=1 \mathrm{~cm} \quad b_{0}=10 \mathrm{~cm}$, respectively. Alavian and Asce (1986) showed Reynolds number and Richardson number are important dimensionless numbers in density currents. Buoyancy flux at the entrance of the channel, Richardson number and density can be derived using following equations.

$$
\begin{aligned}
& B_{0}=\frac{g}{b_{0}} \frac{\rho-\rho_{w}}{\rho_{w}} * Q_{0} \\
& R i_{0}=\frac{B_{0} \times \cos \theta}{U_{0}^{3}}
\end{aligned}
$$

In the above expressions, $\rho_{w}, \rho_{s}, \rho, g$, and $Q_{0}$, represent ambient water density, dry kaolin density, mixture density, gravity acceleration, and inlet discharge, respectively. Inlet Reynolds number $\left(\mathrm{Re}_{0}\right)$ is defined as follows:

$$
R e_{0}=\frac{U_{0} \times z_{0} \times \rho}{\mu}
$$

where $\mathrm{z}_{0}$ is the opening height of the inlet gate which is constant to $1 \mathrm{~cm}$ in all experiments, $\mu$ is the viscosity of the mixture. These data is available in Table 1. The critical Reynolds number in density current is 1000 , so all conducted experiments in this research are turbulent.
Each part of the test is presented by a symbol for example S2Q10C2.5 which states slope of $2 \%$, flow rate of $10 \mathrm{lit} / \mathrm{min}$, and concentration of $2.5 \frac{\mathrm{gr}}{\text { lit }}$. The critical Reynolds number, according to equation (3), in these currents is 1000 , so, all experimental condition given in Table 1, is fully developed turbulent. Also, for all experiments Richardson number is smaller than one so the current is supercritical at the beginning of the channel. A steady, continuous turbidity current is developing in the bed that has a constant, small slope. The $\mathrm{x}$-coordinate is directed down slope tangential to the bed, and the $\mathrm{z}$-coordinate is directed upward normal to the bed. The reduced gravitational acceleration is define by $g^{\prime}=g\left(\rho-\rho_{w}\right) / \rho_{w}$. Layer-averaged current velocity $U_{d}$ and the layer-averaged thickness $h_{d}$ defined by Ellison and Turner (1959) are as follows

$$
\begin{aligned}
& U_{d} h_{d}=\int_{0}^{\infty} U d z \\
& U_{d}{ }^{2} h_{d}=\int_{0}^{\infty} U^{2} d z
\end{aligned}
$$

In all tests, the instantaneous velocities were measured by an Acoustic Doppler Velocimeter (ADV). ADV is very accurate for measuring the mean flow characteristics (Kraus et al. 1994; Lohrmann et al. 1994; Anderson and Lohrmann, 1995; Voulgaris and Trowbridge, 1998; Lopez and Garcia, 2001) but for measuring the turbulence parameters, the accuracy of the ADV is related to characteristics of the flow. Garcia et al. (2005) showed that for using ADV in turbulent flows $F=\frac{L f_{R}}{U_{c}}>20$ where $U_{c}$ is convective velocity, $L$ energy-containing eddy length scale and $f_{R}$ is user-set frequency. Kneller et al. (1999) showed that 
the energy-containing eddy length scale, $L$ approximately equals the thickness of the dense layer. Consequently, in our experiments, $L$ is about $30 \mathrm{~cm} . f_{R}$ is set at $25 \mathrm{~Hz}$. For $F=\frac{L f_{R}}{U_{c}}>20$, convective velocity which is about velocity of the dense layer should be smaller than $37 \mathrm{~cm} / \mathrm{s}$. For all present cases, the maximum velocity of the turbidity layer is smaller than $34 \mathrm{~cm} / \mathrm{s}$. Also, Lohrmann et al. (1994) showed that the error in measuring the Reynolds stress with ADV is about \pm 0.25 in comparison to LDV's results.

Table 1 Inlet conditions for turbidity current experiments

\begin{tabular}{|c|c|c|c|c|c|c|c|c|}
\hline Run & $\begin{array}{c}\bar{U}_{0} \\
(\mathrm{~cm} / \mathrm{s})\end{array}$ & $\begin{array}{c}C_{0} \\
(\mathrm{gr} / \text { lit })\end{array}$ & $S \%$ & $\begin{array}{c}B_{0} \\
\left(\mathrm{~cm}^{3} / \mathrm{s}^{3}\right)\end{array}$ & $R i_{0}$ & $R e_{0}$ & $\begin{array}{c}T_{\text {in }} \\
\left({ }^{0} \mathrm{C}\right)\end{array}$ & $\begin{array}{c}T_{\text {Fluid }} \\
\left({ }^{0} \mathrm{C}\right)\end{array}$ \\
\hline S2Q10C2.5 & 16.7 & 2.5 & 2 & 41 & 0.008 & 1667 & 21 & 21 \\
\hline S2Q10C5.0 & 16.7 & 5 & 2 & 82 & 0.018 & 1667 & 21.5 & 21.5 \\
\hline S2Q10C7.5 & 16.7 & 7.5 & 2 & 123 & 0.027 & 1667 & 21 & 21 \\
\hline S2Q15C2.5 & 25.0 & 2.5 & 2 & 61 & 0.004 & 2500 & 21 & 21 \\
\hline S2Q15C5.0 & 25.0 & 5.0 & 2 & 123 & 0.008 & 2500 & 21 & 21 \\
\hline S2Q15C7.5 & 25.0 & 7.5 & 2 & 184 & 0.012 & 2500 & 21 & 21 \\
\hline S2Q20C2.5 & 33.3 & 2.5 & 2 & 82 & 0.002 & 3333 & 21 & 21 \\
\hline S2Q20C5.0 & 33.3 & 5.0 & 2 & 184 & 0.004 & 3333 & 21 & 21 \\
\hline S2Q20C7.5 & 33.3 & 7.5 & 2 & 245 & 0.007 & 3333 & 20.5 & 20.5 \\
\hline S3Q10C2.5 & 16.7 & 2.5 & 3 & 41 & 0.008 & 1667 & 21 & 21 \\
\hline S3Q10C5.0 & 16.7 & 5.0 & 3 & 82 & 0.018 & 1667 & 21 & 21 \\
\hline S3Q10C7.5 & 16.7 & 7.5 & 3 & 123 & 0.027 & 1667 & 21 & 21 \\
\hline S3Q15C2.5 & 25.0 & 2.5 & 3 & 61 & 0.004 & 2500 & 21 & 21 \\
\hline S3Q15C5.0 & 25.0 & 5.0 & 3 & 123 & 0.008 & 2500 & 21 & 21 \\
\hline S3Q15C7.5 & 25.0 & 7.5 & 3 & 184 & 0.012 & 2500 & 21 & 21 \\
\hline S3Q20C2.5 & 33.3 & 2.5 & 3 & 82 & 0.002 & 3333 & 21 & 21 \\
\hline S3Q20C5.0 & 33.3 & 5.0 & 3 & 184 & 0.004 & 3333 & 21 & 21 \\
\hline S3Q20C7.5 & 33.3 & 7.5 & 3 & 245 & 0.007 & 3333 & 21 & 21 \\
\hline
\end{tabular}

Volgaris and Trwobridge (1998) studied the performance of ADV in turbulent flows. They explained that the ADV is an excellent sensor for obtaining direct covariance measurements of turbulent Reynolds shear stress and the noise levels associated with three acoustic paths are sufficiently equal. Thompson et al. (2003) showed that the results of the ADV and LDV for the stresses near the bed have good coherence. So, using ADV is appropriate for turbulence measurements.

\section{DISCUSSION AND ANALYSIS OF EXPERIMENTAL RESULTS}

Let we define the parameter of turbulence in this research. The instantaneous value for example for the horizontal component of velocity be $U=\bar{U}+u$ where $\bar{U}, u$ is turbulent mean value and a turbulent fluctuation, respectively, Similarly for vertical and lateral component of velocity and particle concentration. The root mean square value of a turbulent fluctuation for example for longitudinal direction be given by $u^{\prime}$ and the turbulence flux covariance terms instance for vertical transport of horizontal momentum be given by $\overline{u w}$.

Profiles of velocity, concentration, turbulent kinetic energy and Reynolds stress for different concentrations and different discharges are shown in Figs. 2, 3 and 4, respectively.

The shape of the velocity profile is governed by the differing and interfering effects of the rigid body and upper diffuse boundaries and can be approximated with the law of the wall up to the velocity maximum and a cumulative Gaussian distribution from the velocity maximum to the ambient interface.

In all experiments concentration profile smoothly increases moving toward the bottom and reaches the maximum value near the bed. These concentration profiles are seen when concentration is low or in saline density currents (Kneller and Buckee, 2001). At constant inlet concentration, when discharge rate increases, the concentration of dense layer increases. This shows that in higher discharges, lower amounts of 
kaolin deposit. As profile of turbulent kinetic energy shows this result is understandable because when the turbulent kinetic energy increases it means that the dense layer is more turbulent and more kaolin particles are suspended in the flow. Increase in the concentration has the opposite effect on the turbulent kinetic energy. All profiles of the turbulent kinetic energy show minima around the maximum velocity which almost is almost compatible with the level of minimum shear stress. Maximum turbulent kinetic energy occurs both near the bed and between the $z_{U_{\max }}$ and the $z_{1 / 2}$ which is about $z / h=0.6$. The Reynolds stress is positive in heights below the $z_{U_{\max }}$, reaches zero over this location, and is negative in the upper layer of the dense layer. Negative values of Reynolds stress is a sign of mixing of fresh water into the current.

Figure 5 shows the velocity distribution for turbidity currents near the wall. The log-law is compatible with experimental values for this current. In these currents, we need to know the von Karman constant $\kappa$ and the integral constant $A$. The most reliable data shows that $\kappa=1 / 2.42$ and $A=1.52$.

$U^{+}=\ln \left(z^{+}\right) / \kappa+A$

Figure 6 shows a comparison between the data for $u^{\prime} / U^{*}, v^{\prime} / U^{*}, w^{\prime} / U^{*}$ plotted against $z^{+}$in the near wall region. High $u^{\prime} / U^{*}, v^{\prime} / U^{*}, w^{\prime} / U^{*}$ occurred close to the bed in all experiment. Fluctuations of the longitudinal velocity in $\mathrm{x}=0.5,1.5 \mathrm{~m}$ is about $30 \%-50 \%$ of the mean velocity. In $\mathrm{x}=2.5$ to $5.5 \mathrm{~m}$ the portion of $u^{\prime}, v^{\prime}$ and $w^{\prime}$ in turbulent kinetic energy is $44 \%, 39 \%$ and $17 \%$. Moving away from the inlet section, fluctuations are reduced because of the viscosity and spreading in $y$ direction. Consequently $u^{\prime}$ in $\mathrm{x}=2.5,3.5 \mathrm{~m}$, is about $20 \%-30 \%$ and in $\mathrm{x}=4.5,5.5 \mathrm{~m}$ is about $10 \%-20 \%$ of the mean velocity. In all stations (except $\mathrm{x}=0.5,1.5 \mathrm{~m}$ ) $u^{\prime} \approx v^{\prime} \neq w^{\prime}$

In stations $\mathrm{x}=0.5,1.5 \mathrm{~m} \frac{v^{\prime}}{u^{\prime}} \approx 0.7, \frac{w^{\prime}}{u^{\prime}} \approx 0.5$ and in other stations $\mathrm{x}>1.5 \mathrm{~m}, \frac{v}{u} \approx 0.9, \frac{w}{u} \approx 0.4$. At the inlet section, the turbulence intensity has the highest level and in all directions turbulence is not isotropic because of the inlet effects and hydraulic jump. In $\mathrm{x}>3.5 \mathrm{~m}$ results show that $u^{\prime} \approx v^{\prime} \cong 1.5 U^{*}$ and $w^{\prime} \cong 0.4 U^{*}$. When discharge increases, the turbulence length scale reduces. As a result turbulence intensity increases. Figures 7 and 8 show that when the discharge increases or concentration increases, the longitude turbulent intensity increases. At the inlet, longitude turbulence intensity has the highest level and in all directions turbulence is anisotropic because of the inlet effects and hydraulic jump. Figure 9 shows the effect of change in the bed slope on the turbulence intensity. There is no visible difference in the normalized turbulence intensity as the bed slope changes.
The vertical distribution of gradient Richardson shows the stable and unstable regions of the stratified flows. This profile is shown in Fig. 10 for supercritical and subcritical flow along the $\mathrm{x}$ direction.

The mean of $R i_{g}$ over the maximum velocity in $\mathrm{x}=0.5 \mathrm{~m}$ (supercritical region) is about $0.11-0.32$ in subcritical region $(x>0.5 \mathrm{~m})$ is larger than 1 .

$R i_{g}=\frac{-g(d \rho / d z)}{\rho_{0}(d U / d z)^{2}}$

\section{INSTRUMENTAL UNCERTAINTY}

The mean value of a fluctuating velocity will vary with each realization. The size of this variation can be estimated as a function of the amplitude and the spectrum of the fluctuations and the duration over which the average is taken. If each individual estimate is independent and unbiased, then the standard deviation of the mean velocity is related to standard deviation of the individual estimates according to following equation:

$\sigma(|U|)=\sigma(U) / n^{0.5}$

where $\sigma(|U|)$ is the standard deviation of the estimates of mean velocity $|U|, \sigma(U)$ is the standard deviation of individual velocity estimates and $n$ is the number of individual estimates used to obtain the mean.

Figure 11 shows an example of spectral analysis of one of our experiments data. The run was chosen for its particularly high noise level to illustrate the parts of the spectrum. The spectrum is a log-log plot, created by log averaging. One consequence is that the spectrum tends to be smoother at high frequencies than at low frequencies because the higher frequencies are averages of more data points. Turbulent spectra can be identified by an inertial region, which falls with a $-5 / 3$ slope (in $\log$-log graphs). The inertial region is visible when it overcomes the Velocimeter's noise floor. Instrumental noise in Velocimeters is white; it has a constant level independent of frequency. Given the noise level and the sample rate, one can compute the short-term uncertainty using the equation

$\sigma(U)=\left(F_{s} S_{n} / 2\right)^{0.5}$

where $F_{s}$ is the sample rate of frequency. $S_{n}$ is the noise spectrum.

Where $F_{s}$ is the sample rate of frequency, $S_{n}$ is the noise spectrum., noise level In Fig. 11, is $0.001(\mathrm{~m} / \mathrm{s})^{2} / \mathrm{Hz}$ and a sample rate in this noise level is $5 \mathrm{~Hz}$. According to the equation (8), we would predict an uncertainty. So, the short term uncertainty is $0.05 \mathrm{~m} / \mathrm{s}$. the standard deviation of the mean velocity, according to the equation (7), is $0.008 \mathrm{~m} / \mathrm{s}$.

Figure 12a presents mean velocities as a function of sample rate. Each mean value was an average of observed velocity over the 40-s duration of the run. The means and standard deviations plotted in Fig. 12 were 
computed using all available runs and all available sample volumes at each given sample rate. The solid black line was the average of all the mean velocities. The dashed black lines represent error bounds based on the predicted uncertainty of the mean velocities. Figure $12 \mathrm{~b}$ shows how mean velocity varies with sample volume. The only large deviations from the means occur with $3 \mathrm{~mm}$ sample volume at sample rates of $25 \mathrm{~Hz}$.

Figure 13a shows how standard deviation varies with sample rate. Standard deviation should increase with sample rate. The amount of increase depends on the spectrum. Figure 13b shows how standard deviations vary with sample volume. The standard deviation is relatively constant for all sample volumes and sample rates except the smallest sample volume $(3 \mathrm{~mm})$ and the fastest sample rate $(25 \mathrm{~Hz})$.

In general, $3 \mathrm{~mm}$ sample volume produces a substantially higher noise level, but the added noise is insignificant at sample rates of 1 and $5 \mathrm{~Hz}$. The higher noise level may also fall below the turbulent spectra when sampled at $25 \mathrm{~Hz}$. But, $9 \mathrm{~mm}$ sample volume produces insignificant noise at higher sample rate in this instrument, i.e. $25 \mathrm{~Hz}$. So, we could use the maximum sample rate when we set the sample volume in $9 \mathrm{~mm}$.

\section{Conclusion}

The three-dimensional Acoustic-Doppler Velocimeter (ADV) was used to measure the instantaneous velocity and characteristics of the turbulent flow. The series of experiment were conducted in a three-dimensional channel for different discharge flows, concentrations, and bed slopes. Results are expressed for all flow rates, slopes and concentrations as the distribution of turbulence energy, Reynolds stress and the turbulent intensity. All profiles of turbulent kinetic energy show minima around the maximum velocity which almost is compatible with the level of minimum shear stress. Maximum turbulent kinetic energy occurs both near the bed and between the $z_{U_{\max }}$ and the $z_{1 / 2}$ where the large eddies are generated, in this study, this point is about $z / h=0.6$. Also increased discharge will result in increased turbulence kinetic energy. It should be mentioned that increased concentration will result in decreased turbulent kinetic energy which may be because of the increase in damping due to the viscous force. Reynolds stress is positive in heights below the $z_{U_{\max }}$ and it reaches to the zero over this location and it has negative amounts in the upper layer of the dense layer. The second constant of log-law is not compatible with experimental values for this current. All three component of the turbulence intensity are decreased gradually as $z^{+}$increases. In $\mathrm{x}>3.5 \mathrm{~m}$ results show that $u^{\prime} \approx v^{\prime} \cong 1.5 U^{*}$ and $w^{\prime} \cong 0.4 U^{*}$. There is no visible difference in the normalized turbulence intensity as the bed slope changes. The amounts of $R i_{g}$ is about 0.11 0.32 in the supercritical region $(x=0.5 \mathrm{~m})$, which reveals that the outer region of the current is unstable.

\section{ACKNOWLEDGMENTS}

The authors gratefully acknowledge the Center of Excellence in Energy Conversion, School of Mechanical Engineering, and Research deputy of Sharif University of Technology who supported these experiments.

\section{REFERENCES}

Alavian, V. and A.M. Asce (1986). Behavior of density currents on an incline. J. Hydrol. Eng. 112, 27-42.

Anderson, S. and A. Lohrmann (1995). Open Water Test of the SonTek Acoustic Doppler Velocimeter. Proc. IEEE Fifth Work. Conf on Curr. Measurements, 188-92.

Best, J.L., A.D. Kirkbride and J. Peakall (2001). Mean Flow and Turbulence Structure in Sediment-Laden Gravity Currents: New Insights Using Ultrasonic Doppler Velocity Profiling. Spec. Publs. int. Ass. Sediment 31, 159-172.

Buckee, C., B. Kneller and J. Peakall (2001). Turbulence Structure in Steady, Solute-Driven Gavity Currents, Sediment transport and deposition by particulate gravity currents. Spec. Publs. int. Ass. Sediment 31, 173-189.

Britter, R.E. and P.F. Linden (1980). The motion of the front of a gravity current travelling. down an incline. J. Fluid Mech. 99, 531-543.

Britter, R.E. and J.E. Simpson (1978). Experiments on the dynamics of a gravity current head. J. Fluid Mech. 88 (2), 223-240.

Edwards, D.E., M.R. Leeder, J.L. Best and H.M. Pantin (1994). An experimental study of reflected density currents and the interpretation of certain turbidites. Sedimentology 41, 437-461.

Elder, R.A. and W.P. Wunderlich (1972). Inflow density, currents in reservoirs. Proceedings of International Symposium on Stratified Flows, ASCE, 221-236.

Ellison, T.H. and J.S. Turner (1959). Turbulent Entrainments in Stratified Flows. J. Fluid Mech. 6, 423-448.

Garcia, C.M., M.I. Cantero, Y. Nino and M.H. Garcia (2005). Turbulence Measurements with Acoustic Doppler Velocimeters. J. Hydraulic Eng., ASCE 131, 1062-1073.

Garcia, M.H. (1994). Depositional Turbidity Currents Laden with Poorly Sorted Sediment. J. Hydraulic Eng., ASCE 120, 1240-1263.

Hebbert, B., J. Patterson, I. Loh and J. Imberger (1979). Collie River. underflow into the Wellington reservoir. J. Hydraulic Div., ASCE 105(5), 533545 . 
Kneller, B.C., S.J. Bennett and W.D. McCaffrey (1999). Velocity Structure, Turbulence and Fluid Stresses in Experimental Gravity Currents. $J$. Geophys. Res. 104 (C3), 5381-5391.

Kneller, B.C., S.J. Bennett and W.D. McCaffrey (1997). Velocity and turbulence structure of gravity currents and internal solitary waves: potential sediment transport and the formation of wave ripples in deepwater. Sedimentary Geology 112, 235-250.

Kraus, N.C., A. Lohrmann and R. Cabrera (1994). New Acoustic Meter for Measuring 3D Laboratory Flows. J. Hydraulic Eng. 120, 406-412.

Lohrmann, A., R. Cabrera and N.C. Kraus (1994). Acoustic-Doppler Velocimeter (ADV) for laboratory use. Fundamentals and advancements in hydraulic measurements and experimentation Proceedings, Hydraulic Division, ASCE, 351-365.

Lopez, F. and M.H. García (2001). Open-Channel Flow Through Simulated Vegetation: Mean Flow and Turbulence Modeling. Journal of Hydraulic Engineering 127(5), 392-402.

Pantin, H.M. and M.R. Leeder (1987). Reverse Flow in Turbidity Currents: the Role of Internal Solitons. Sedimentology 34(6), 1143-1155.

Simpson, J.E. and R.E. Britter (1979). The Dynamics of the Head of a Gravity Current Advancing over a Horizontal Surface. J. Fluid Mech. 94, 477-495.
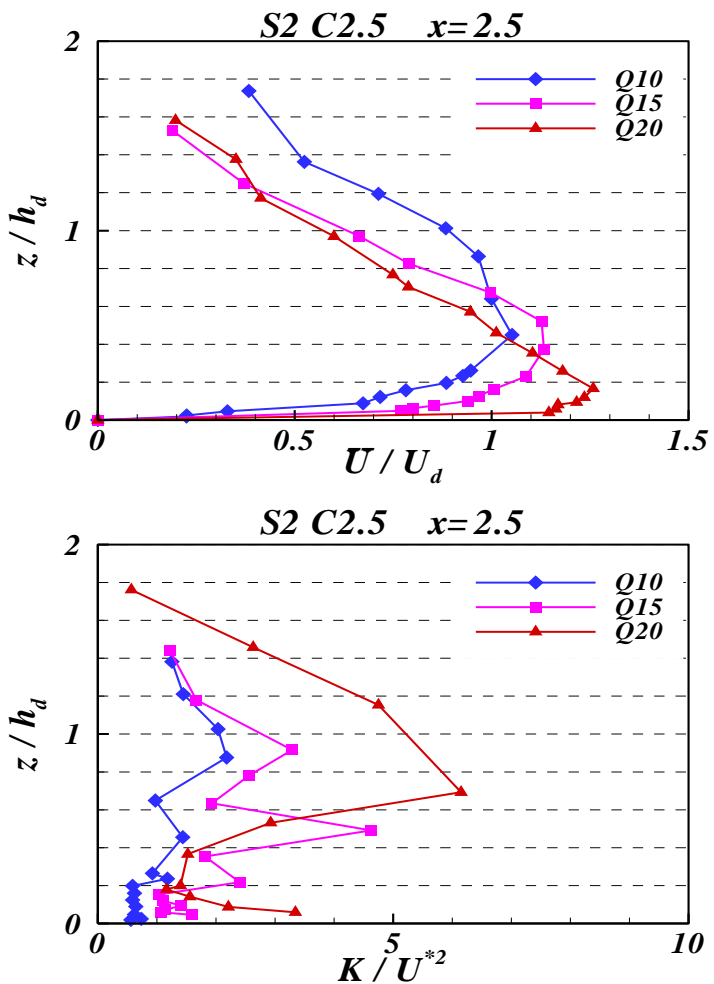

Thompson, C.E.L., C.L. Amos, T.E.R. Jones and J. Chaplin (2003). The manifestation of fluidtransmitted bed shear stress in a smooth annular flume: a comparison of methods. Journal of Coastal Research 19, 1094-1103.

Voulgaris, G. and J.H. Trowbridge (1998). Evaluation of the Acoustic-Doppler Velocimeter (ADV) for Turbulence Measurements. J. Atmos. Oceanic Technology 15, 272-289.
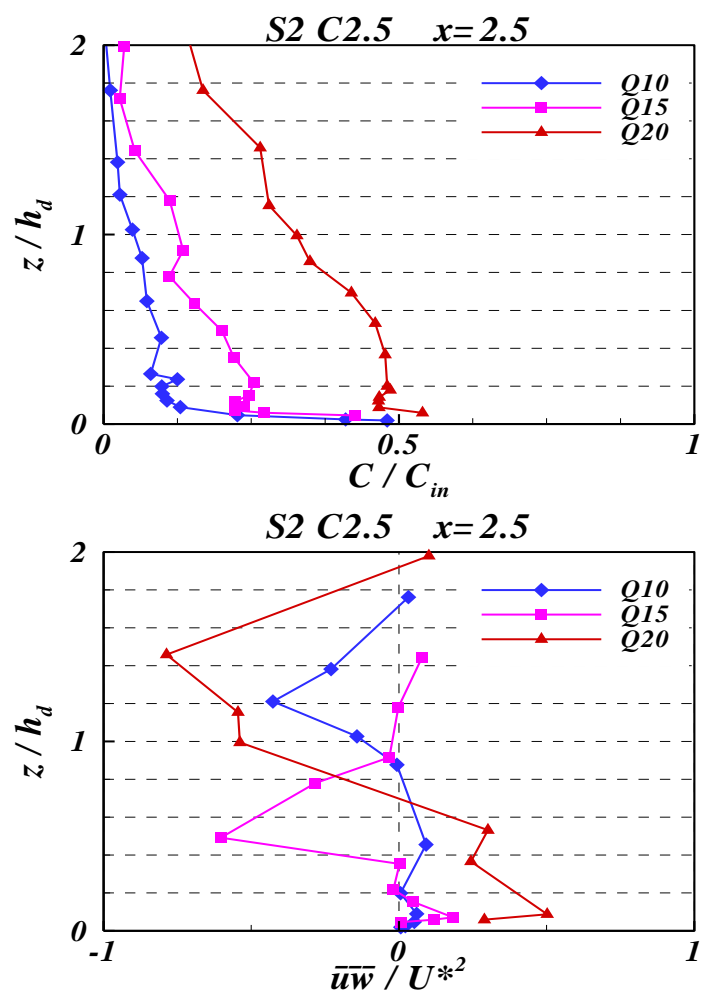

Fig. 2. Velocity, Concentration, turbulent kinetic energy and Reynolds stress profiles in Slope $=2 \%$ and Concentration $=2.5 \mathrm{~g} / \mathrm{lit}$ 

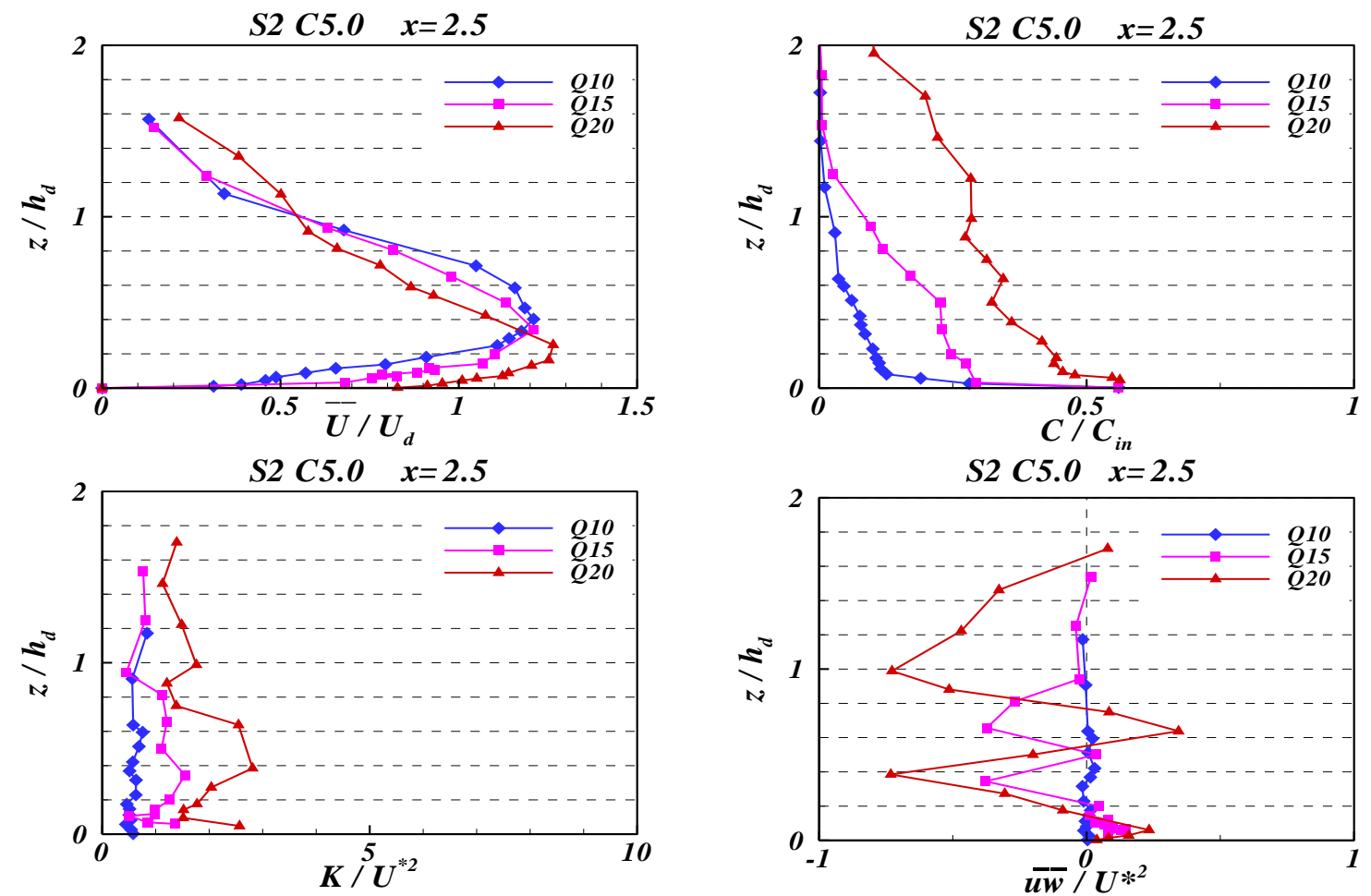

Fig. 3. Velocity, Concentration, turbulent kinetic energy and Reynolds stress profiles in Slope $=2 \%$ and Concentration $=5.0 \mathrm{~g} / \mathrm{lit}$
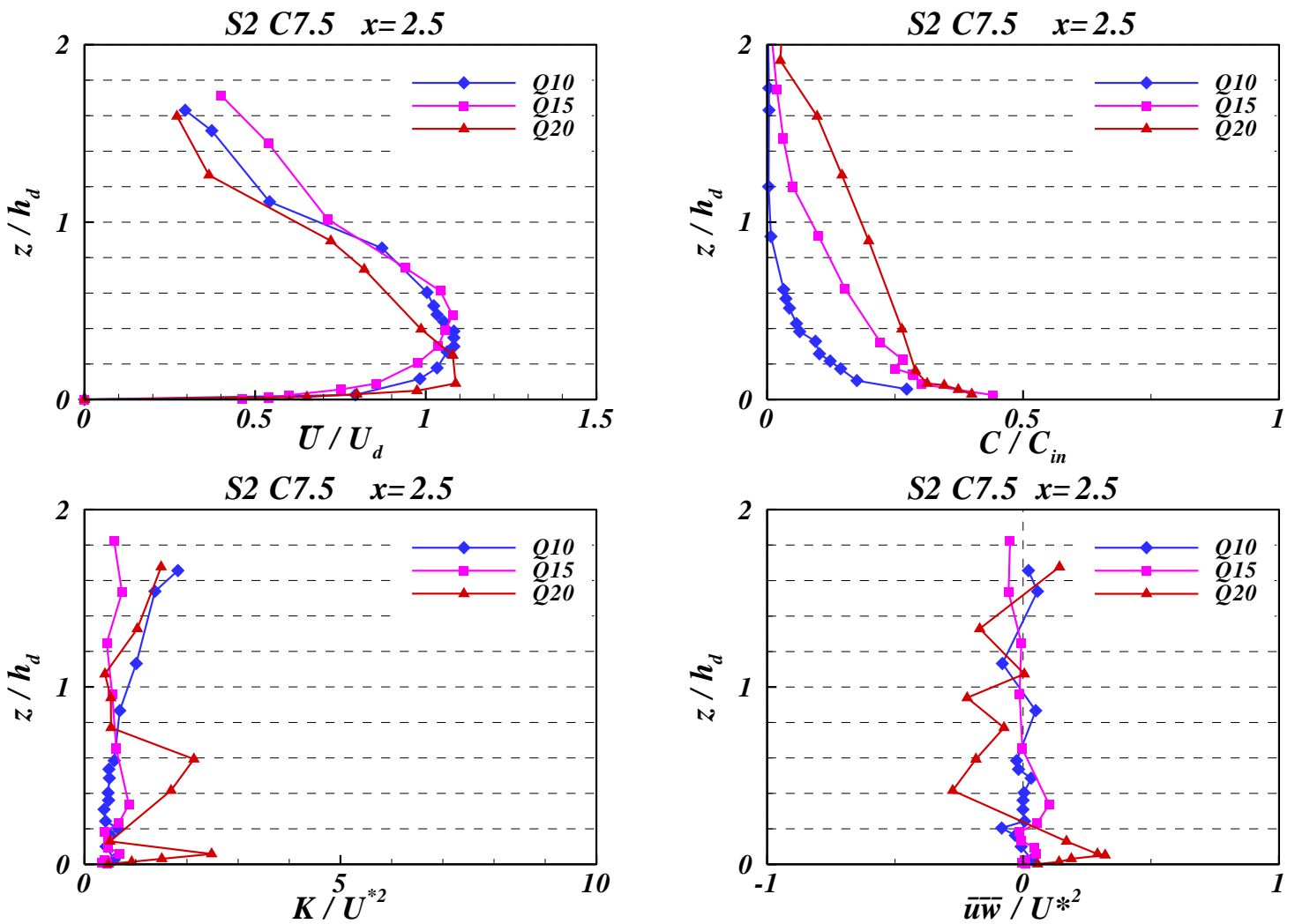

Fig. 4. Velocity, concentration, turbulent kinetic energy and Reynolds stress profiles in Slope $=2 \%$ and Concentration $=7.5 \mathrm{~g} / \mathrm{lit}$ 


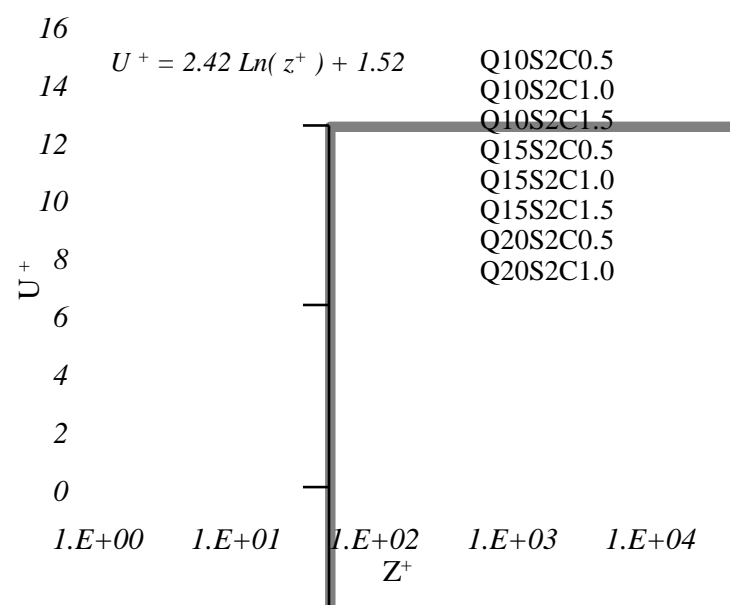

Fig. 5. Log-law plots of mean velocity for turbidity current
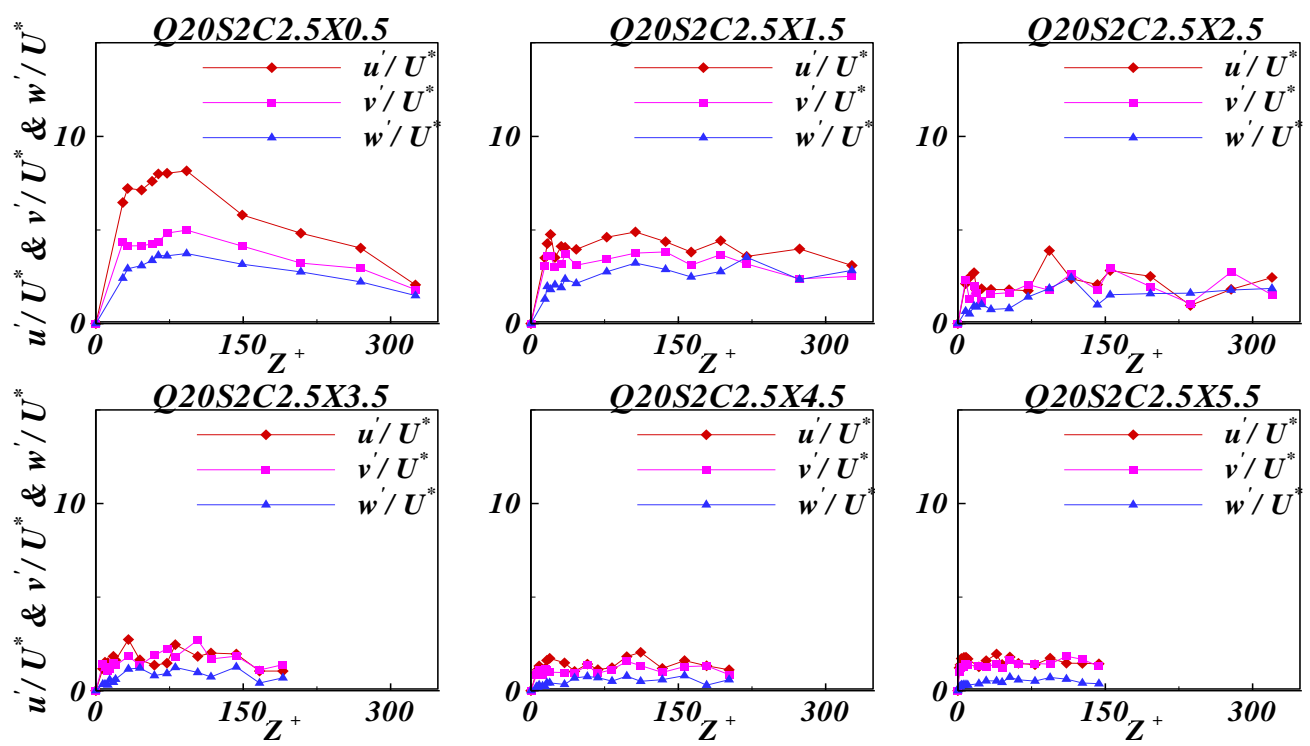

Fig. 6. Effect of distance from inlet section on turbulence intensity
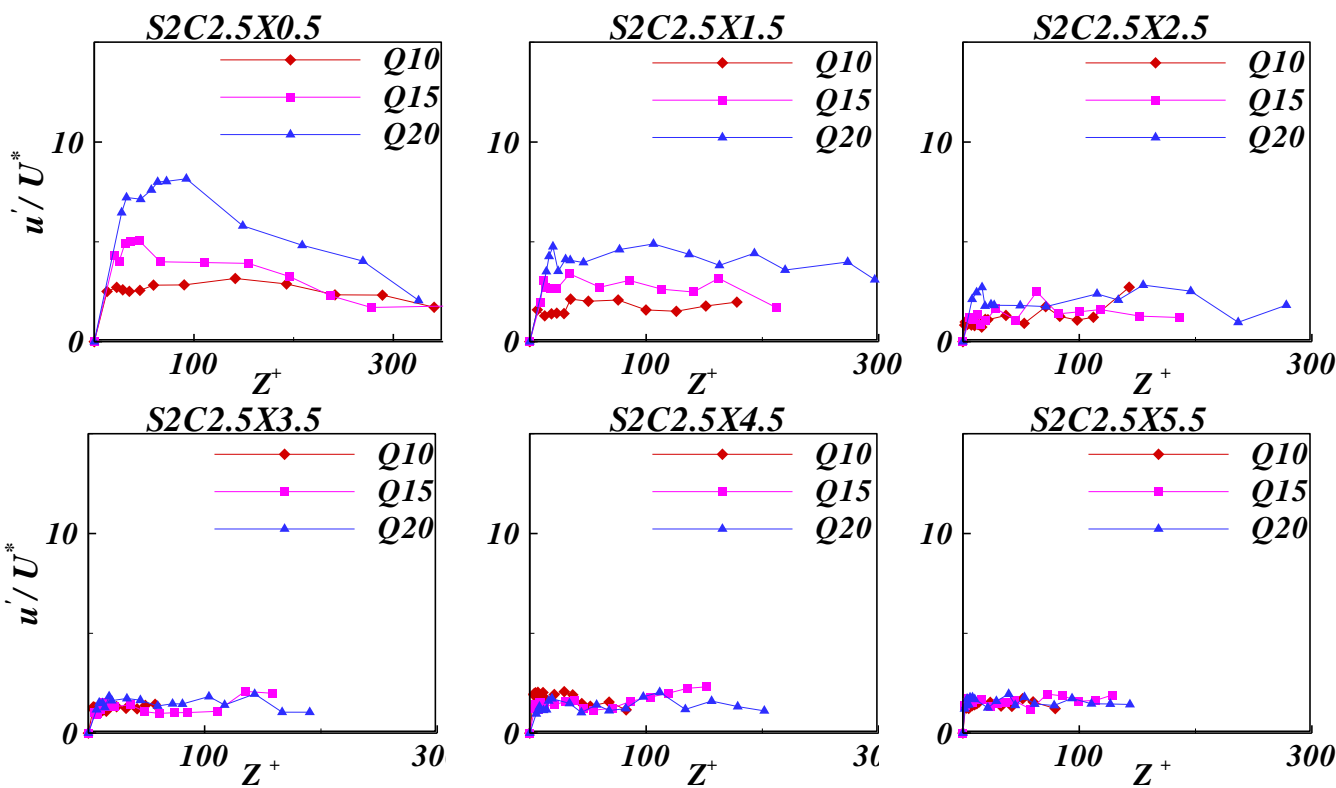

Fig. 7. Effect of discharge on turbulence intensity 

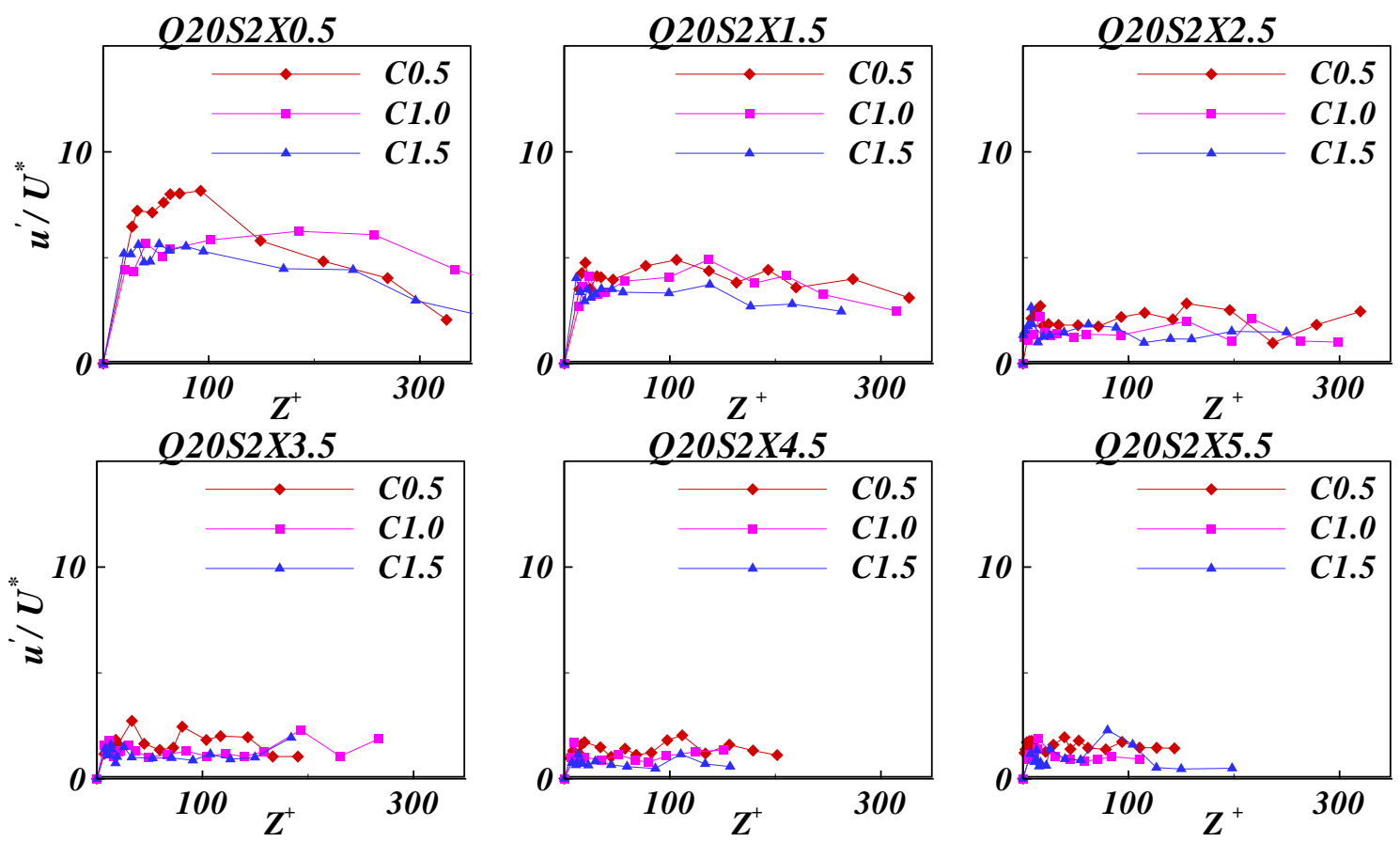

Fig. 8. Effect of concentration on turbulence intensity
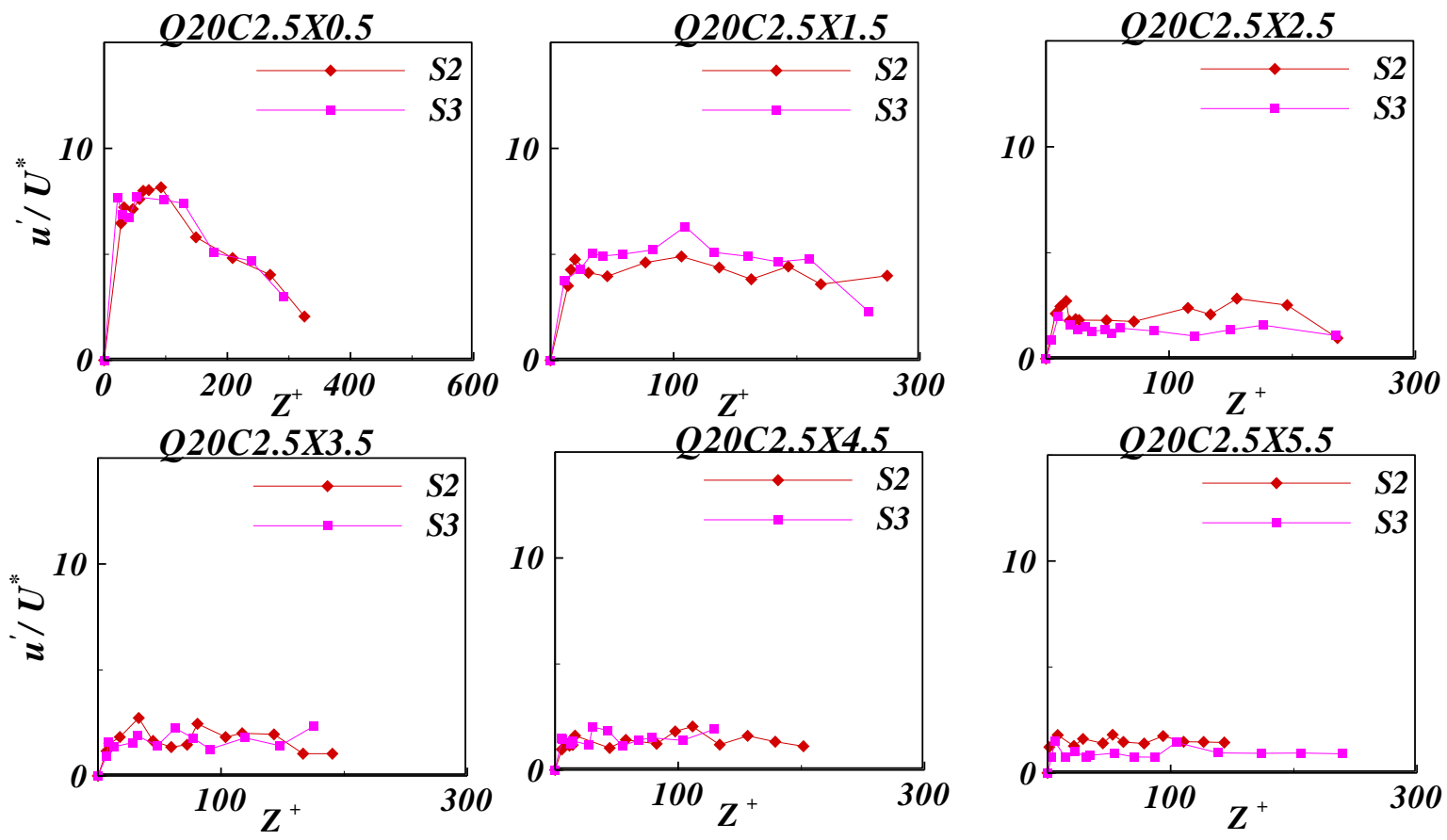

Fig. 9. Effect of slope on turbulence intensity 


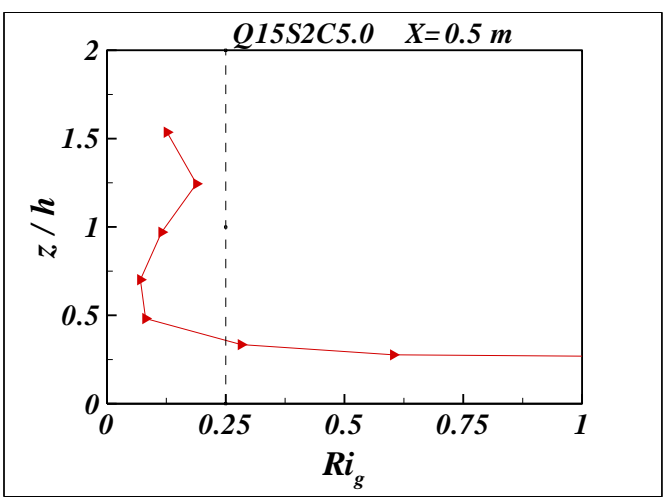

Fig. 10. Vertical distribution of gradient Richardson

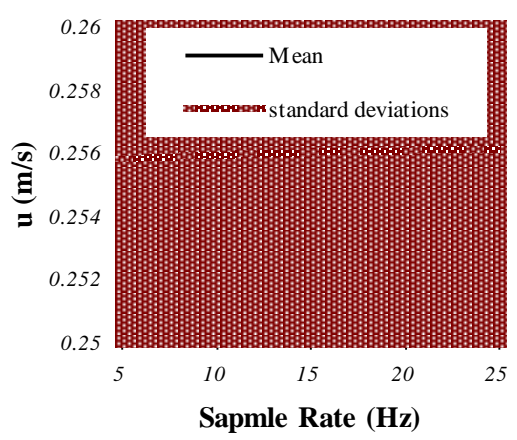

(a)

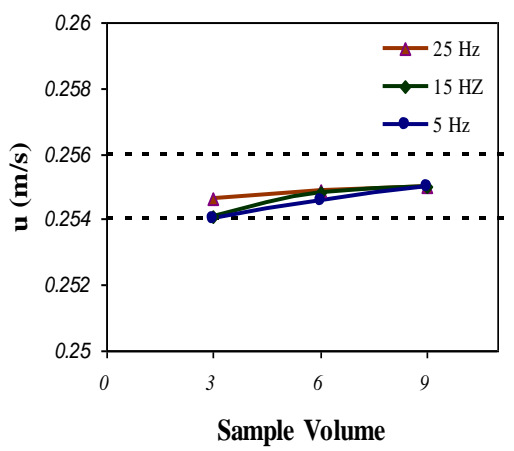

(b)

Fig. 12. Mean velocity versus sample rate and sample volume

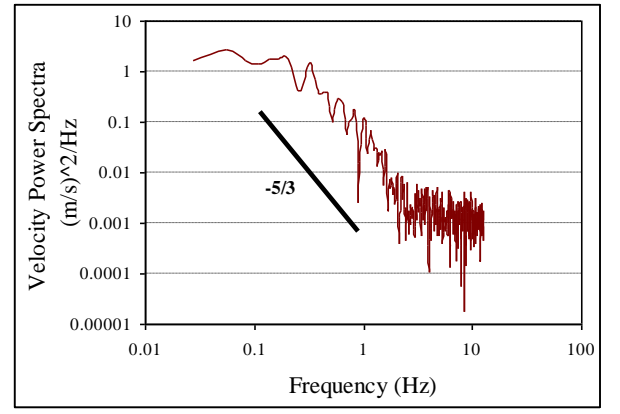

Fig. 11.Velocity power spectra versus Frequency

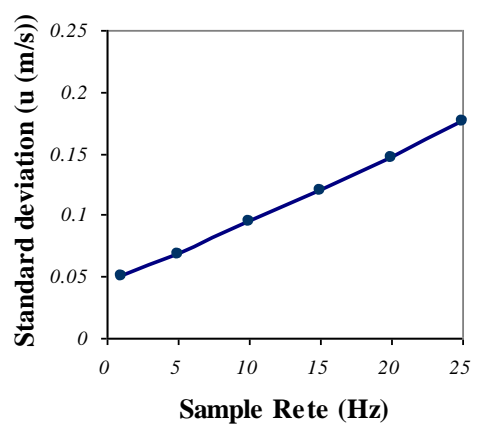

(a)

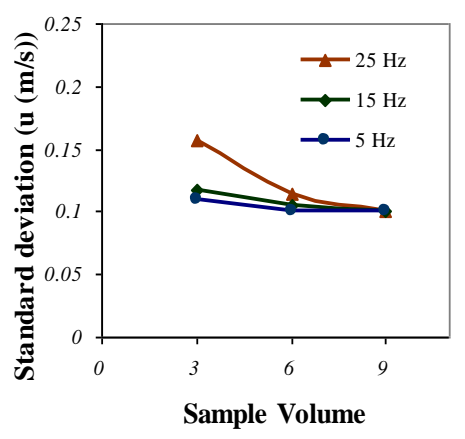

(b)

Fig. 13. Mean velocity versus sample rate and sample volume 